\title{
The Improvement of Phytomediation on the Treatment Effectiveness of Heavy Metals with Energy Sunflower Plants with Calcium Peroxide and Phytohormones
}

\author{
T. Y. Yeh \\ Department of Civil and Environmental Engineering, National University of Kaohsiung, Taiwan \\ Email: tyyeh@nuk.edu.tw
}

Received 12 May 2015; accepted 24 October 2015; published 27 October 2015

Copyright (C) 2015 by author and Scientific Research Publishing Inc. This work is licensed under the Creative Commons Attribution International License (CC BY). http://creativecommons.org/licenses/by/4.0/

(c) (i) Open Access

\section{Abstract}

Phytomediation is an environmentally friendly green rehabilitation technology that is often incorporated with an application to improve calcium peroxide and phytohormones required for the growth of agricultural plants with the expectation to improve the effectiveness of plant rehabilitation. This study mainly consists of two parts: 1) water culture experiment and 2) pot culture experiment. In the water culture experiment, we attempt to understand the influence of the addition of calcium peroxide, phytohormones (IAA and $\mathrm{GA}_{3}$ ) and a chelating agent on the growth of sunflower plants. From the growth, we are then able to know the effectiveness of the addition of phytohormones. However, in the pot culture experiment, when hormones and the chelating agent EDTA are introduced to different plant groups at the same time, if the nutrition in the water required by plants is not available, the addition of the hormone cannot negate the toxicity caused by EDTA. In terms of calcium peroxide, due to quick release of oxygen in water, this study fails to apply calcium peroxide to the water culture experiment. When the pot culture experiment is used to examine the influence of hormones at different concentration levels on the growth of sunflowers, $\mathrm{GA}_{3} \mathbf{1 0}^{-8} \mathrm{M}$ is reported to have the optimal effectiveness, followed by IAA $10^{-8} \mathrm{M}$; IAA $10^{-12} \mathrm{M}$ has the lowest effectiveness. According to an accumulation analysis of heavy metals at different levels, $\mathrm{GA}_{3}$ concentrates in leaves to transport nutrition in soil to leaves. This results in an excellent TF value of $2.329 \mathrm{G}$ of $\mathrm{GA}_{3}$ than 1.845 of the control group indicating that the addition of the hormone and chelating agent to $\mathrm{GA}_{3}$ increases the $\mathrm{TF}$ value and the chelating agent is beneficial to the sunflower plant. If we examine phytoattenuation ability, the one-month experiment was divided into three stages for ten days each. The concentration level of heavy metals in the soil at each stage dropped continuously while that of the control group decreased from $31.63 \mathrm{mg} / \mathrm{kg}$ to $23.96 \mathrm{mg} / \mathrm{kg}, \mathrm{GA}_{3}$ from $32.09 \mathrm{mg} / \mathrm{kg}$ to $23.04 \mathrm{mg} / \mathrm{kg}$ and EDTA from $30.65 \mathrm{mg} / \mathrm{kg}$ to $25.93 \mathrm{mg} / \mathrm{kg}$ indicating the quickest growth period of the sunflowers from the formation of the bud to blossom. During the 
stage, the quick upward transportation of nutrition results in quick accumulation of heavy metals; the accumulated speed of heavy metals is found higher than that of directly planted plants. This study shows an improvement in the effectiveness of the addition of hormones on plant extraction and when rehabilitation is incorporated with sunflowers with the beginning bud formation, better treatment effectiveness can be reached.

\section{Keywords}

\section{Phytomediation, Heavy Metal Cooper, Chelating Agent EDTA, Energy Plant (Sunflower), Hormones} (IAA, GA ${ }_{3}$ ), Phytoattenuation

\section{Introduction}

Recently, soil contamination sites including Dapingding Special District (10 hectares), Dading Feed Manufacturing in Wandang, Pingtung County (0.58 hectares) and Cishan Rock in Xinyuan (4.77 hectares) are challenged with issues of spaciousness and deep and heavy contamination and if commonly adopted technologies such as reverse dilution, soil acid washing, and turn over are used, it is estimated to require a huge amount of expenditure. Green remediation, thus, has become a possible treatment method for these sites based on risk consideration. Green remediation includes the use of solar panels, wind turbines, and biological energy such as the phytoattenuation of sunflowers and after the barrier and monitoring planning of effective and necessary risk evaluation, it can be used to replace the common practices of soil treatment technology [1].

Phytomediation is a part of ecological engineering that is more economical and sustainable in resource utilization than traditional physical and chemical treatments. Additionally, phytomediation can also be applied to the complicated combinations of organic and inorganic substance contamination as well as sediment or soil mediation. It is unlikely to damage soil structure and texture with higher public acceptance in the treatment and mediation area, better improve the friendliness of the green landscape. Phytomediation mechanisms consist of phytoextraction, phytostabilization and rhizofiltration. There are two pathways for plants to accumulate heavy metals and transport to the parts on the ground. The first is the symplast transport pathway. It uses the channel of the root hair cell membrane to allow for the entrance of ions and water as well as transportation between cells. Heavy metals enter vessel cells inside the root via the cortex, endodermis, and pericycle. This type of transportation is active and will select necessary metal ions (such as copper and zinc) as well as unnecessary ones (such as cadmium and lead). Another is the apoplast pathway. It moves along the gap of the cell walls by utilizing diffusion and convective transport after absorption by the roots. When heavy metals are transported from cortex to endodermis, the water-resistant Casparin strip bars the transportation of water and ions. The root surface of plants contains carboxyl and the root that absorbs cations plays an important role. After the addition of a chelating agent, metal cations form a sulfato complex. The positive electron charge is then transferred into a positive electron charge [2]. Transportation does not make use of the absorption of carboxyl at the root but damages the Casparian strip mechanism to transport the metal-chelating agent complex to the parts of plant above the ground to obtain a phytomediationresult [3].

\section{Experimental Material and Method}

\subsection{Experimental Equipment}

1) Atomic Absorption Spectrophotometer;

2) MarsX microwave;

3) Delta-T Scan;

4) Vacuum filtering device ROCKER 400 manufactured by Today's; and

5) Electronic weighing scale GR-200 manufactured by AND.

\subsection{Experimental Material}

1) Heavy metal: $\mathrm{CuSO}_{4}, \mathrm{~Pb}\left(\mathrm{NO}_{3}\right)_{2}$, and $\mathrm{ZnCl}_{2}$; 
2) Phytohormones: Indole-3-acetic-acid $\left(\mathrm{C}_{10} \mathrm{H}_{9} \mathrm{NO}_{2}\right)$, Gibberellic acid $\left(\mathrm{C}_{19} \mathrm{H}_{22} \mathrm{O}_{6}\right)$;

3) Chelating agents: EDDS $\left(\mathrm{C}_{10} \mathrm{H}_{13} \mathrm{~N}_{2} \mathrm{Na}_{3} \mathrm{O}_{8}\right)$, EDTA $\left(\mathrm{C}_{10} \mathrm{H}_{16} \mathrm{~N}_{2} \mathrm{O}_{8}\right)$; and

4) Other agent: calcium peroxide $\left(\mathrm{CaO}_{2}\right)$.

\subsection{Analysis Method}

The experimental methods described below primarily analyze phytomorphology, soil parameters, heavy metals and the bacteria of plant roots and soil interface.

\subsubsection{Phytomorphology}

Because plants absorb heavy metals mainly via the transportation function of their roots, root morphology decides phytomediation effectiveness. This study attempts to use a Delta-T Scan to analyze the relevant root morphology parameters of sunflowers including root length, diameter, size, and body surface area and examine the relevance of accumulated heavy metals in plants. Furthermore, the dry biomass of the plants' roots, stem, leaves, and flower is weighed after drying at $60^{\circ} \mathrm{C}$.

\subsubsection{Analysis of Heavy Metals in Plants}

Plants were dried at $104^{\circ} \mathrm{C}$ for 24 hours and the roots, stem, leaves, and flower were grounded. The portion of $0.5 \mathrm{~g}$ was taken to add concentrated nitric acid at the volume of $12 \mathrm{~mL}$. MarasX microwave was used for extraction and then Atomic Absorption Spectrohpotometer was used for analysis.

\subsubsection{Heavy Metals Analysis}

This study uses the aqua regia digestion method to extract total heavy metal $\mathrm{Cu}$ weight contained in the soil in the pot culture experiment. Soil was baked at $104^{\circ} \mathrm{C}$ in the oven and after filtering with \#20 mesh, $0.5 \mathrm{~g}$ soil was mixed with concentrated nitric acid and concentrated hydrochloric acid at the volumes of $3.0 \mathrm{~mL}$ and $9.0 \mathrm{~mL}$, respectively, with MarsX microwave for microwave absorption. AA was also used for analysis.

The roots, stem, leaves, and flower of the sunflower were dried in the oven at the temperature of $104^{\circ} \mathrm{C}$ for 24 hours and the resulting dried parts were grounded. A portion of $0.5 \mathrm{~g}$ was added with concentrated nitric acid and hydrochloric acid at the volumes of $5.5 \mathrm{~mL}$ and $0.5 \mathrm{~mL}$, respectively, with MarsX microwave for microwave absorption. AA was also used for analysis. The parameters of microwave supplementary absorption are set as in Table 1.

\section{Experimental Results and Discussion}

\subsection{Pot Culture Experiment I}

This study attempts to address the variance of sunflower growth in soil contributed by hormones at different concentration levels. Literature review used hormone concentrations between $10^{-8} \mathrm{M}-10^{-12} \mathrm{M}$ and suggestions were proposed for the toxicity of plants when the concentration level is lower than $10^{-6} \mathrm{M}$. Thus, this study, in addition to the control group, designed five experimental groups: IAA $10^{-8} \mathrm{M}$, IAA $10^{-12} \mathrm{M}, \mathrm{GA}_{3} 10^{-8} \mathrm{M}$, and $\mathrm{GA}_{3} 10^{-12} \mathrm{M}$. The soil used was from the sunflower field at the National University of Kaohsiung (contained low organic substances) while a hormone was administered to the leaves by spraying during daily irrigation until the leaves became wet. The experimental purpose is to discuss whether variance of sunflower growth results from hormones at different concentration levels through daily photo taking and observation and expects to discover the optimal application of hormone concentration that can be applied to future pot culture experiments.

Phytomorphology Analysis of Pot Culture Experiment I

The experimental interval was one month and the growth is shown in Diagrams 1-5. According to an initial ob-

Table 1. Microwave supplementary absorption parameter setup.

\begin{tabular}{|c|c|c|c|c|}
\hline & Power (W) & Ramp (min) & Temperature $\left({ }^{\circ} \mathrm{C}\right)$ & Hold time (min) \\
\hline Total extraction volume of soil & $1600(75 \%)$ & $15: 00$ & 200 & $15: 00$ \\
\hline Plant extraction & $1600(75 \%)$ & $15: 00$ & 200 & $15: 00$ \\
\hline
\end{tabular}



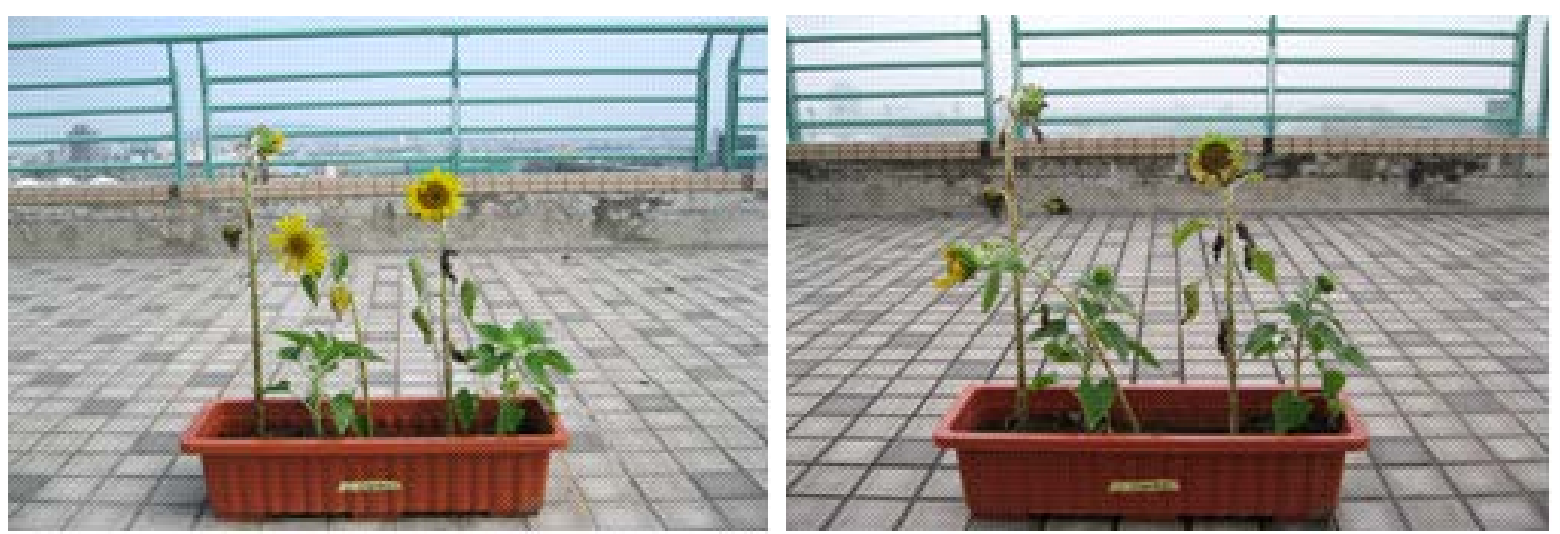

Diagram 1. Growth of control group before and after pot culture experiment 1.
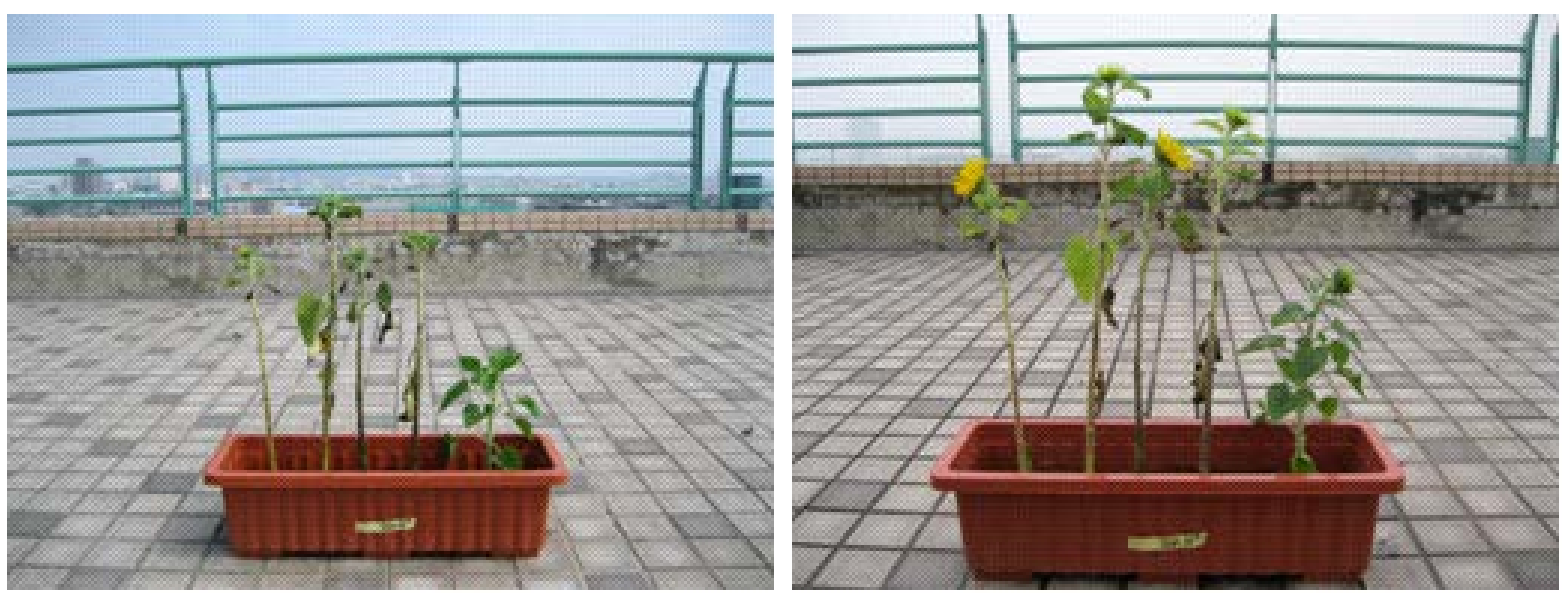

Diagram 2. Growth of IAA $10^{-8} \mathrm{M}$ before and after pot culture experiment 1.
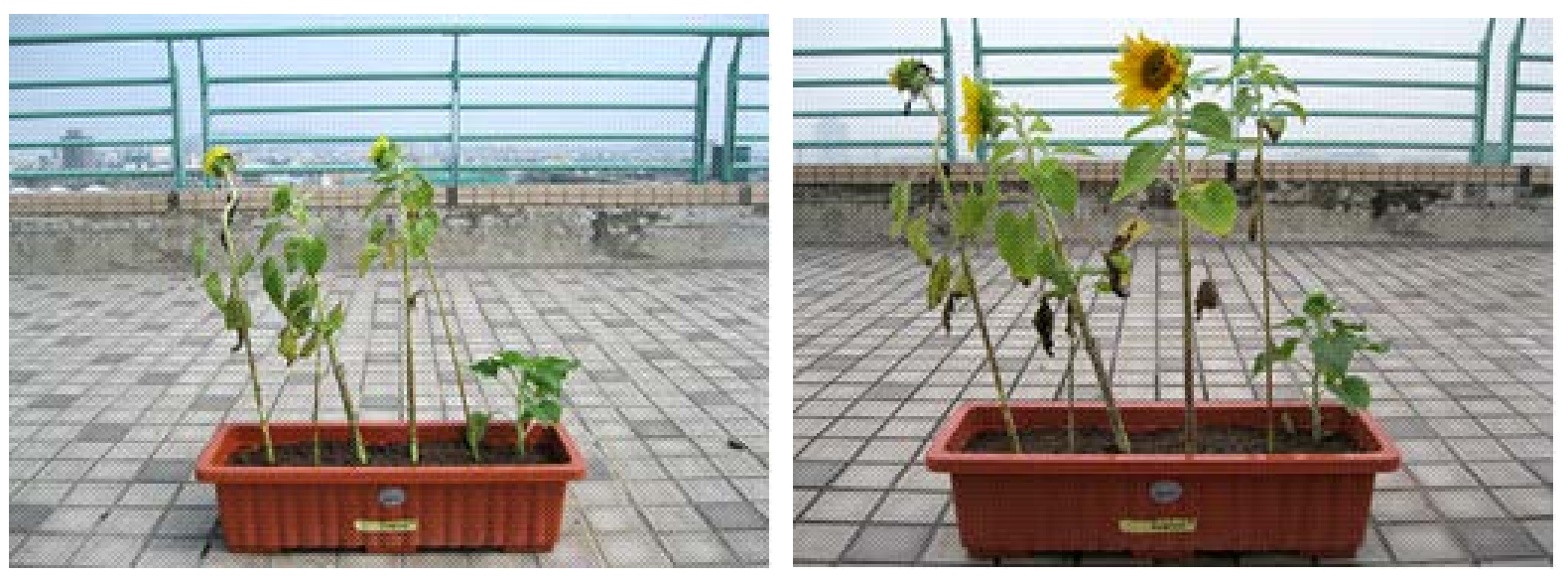

Diagram 3. Growth of IAA $10^{-12} \mathrm{M}$ before and after pot culture experiment 1.

servation from the photos, the growth of plants added with hormones outperforms the control growth but the comparison of IAA $10^{-8} \mathrm{M}$, IAA $10^{-12} \mathrm{M}, \mathrm{GA}_{3} 10^{-8} \mathrm{M}$ and $\mathrm{GA}_{3} 10^{-12} \mathrm{M}$ failed to determine a growth variance that results from the hormones at different concentration levels. The growth of five groups in the one-month interval is shown in Diagram 6, the control group increased by approximately $6.102 \mathrm{~cm}$, IAA $10^{-8} \mathrm{M}$ by $7.808 \mathrm{~cm}$, IAA $10^{-12} \mathrm{M}$ by $6.07 \mathrm{~cm}, \mathrm{GA}_{3} 10^{-8} \mathrm{M}$ by 11.40 , and $\mathrm{GA}_{3} 10^{-12} \mathrm{M}$ by about $7.358 \mathrm{~cm}$. After a spraying of the same hormone, the comparison shows that the growth of $10^{-8} \mathrm{M}$ outperformed $10^{-12} \mathrm{M}$. Among them, $\mathrm{GA}_{3} 10^{-8} \mathrm{M}$ 

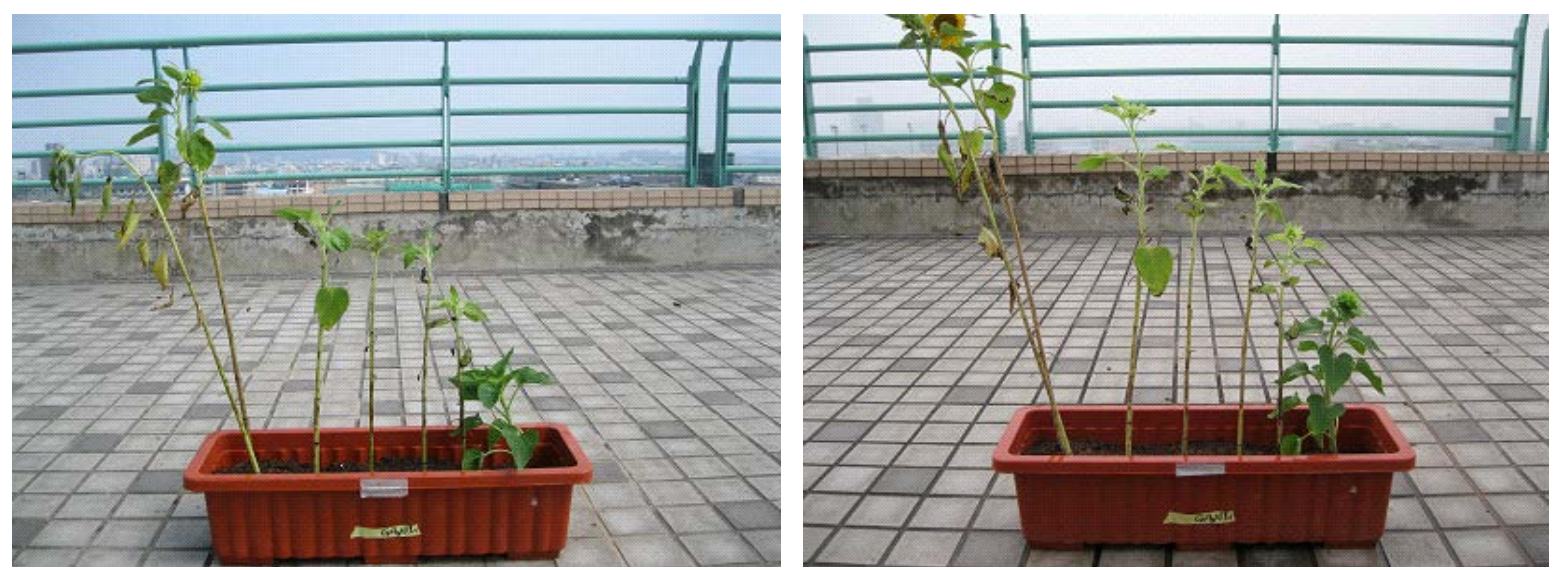

Diagram 4. Growth of $\mathrm{GA}_{3} 10^{-8} \mathrm{M}$ before and after pot culture experiment 1.
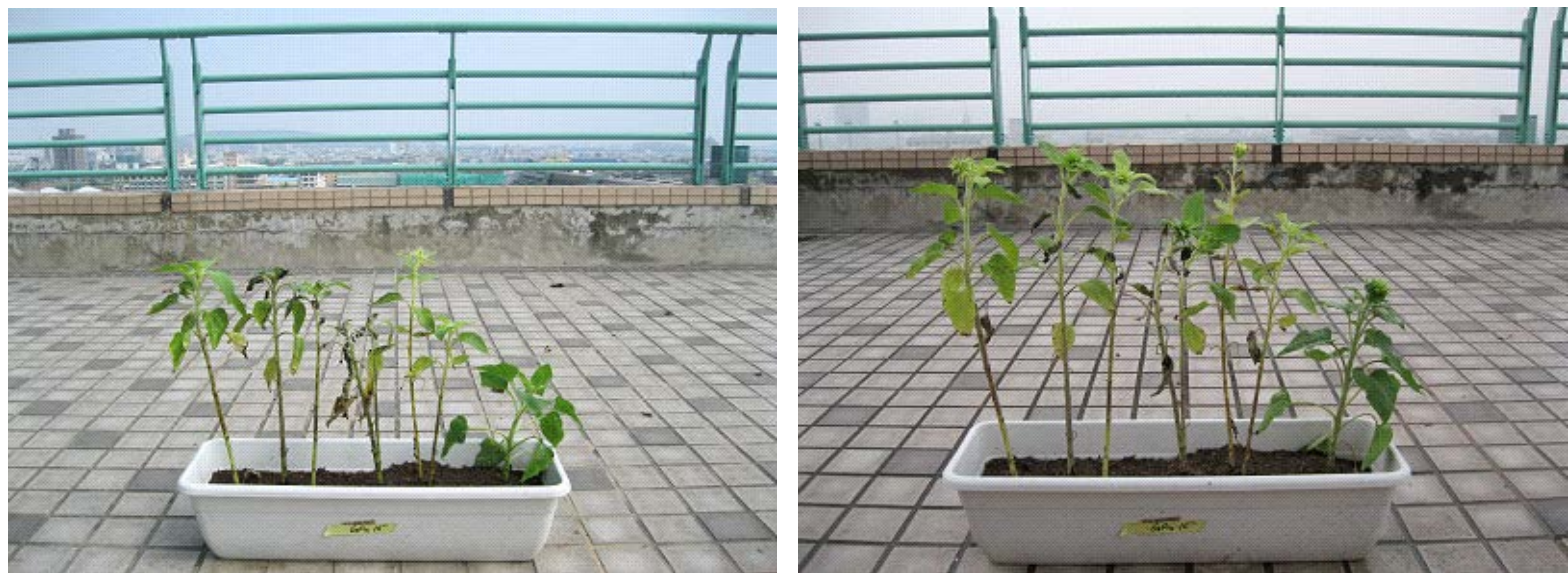

Diagram 5. Growth of $\mathrm{GA}_{3} 10^{-12} \mathrm{~m}$ before and after pot culture experiment 1.

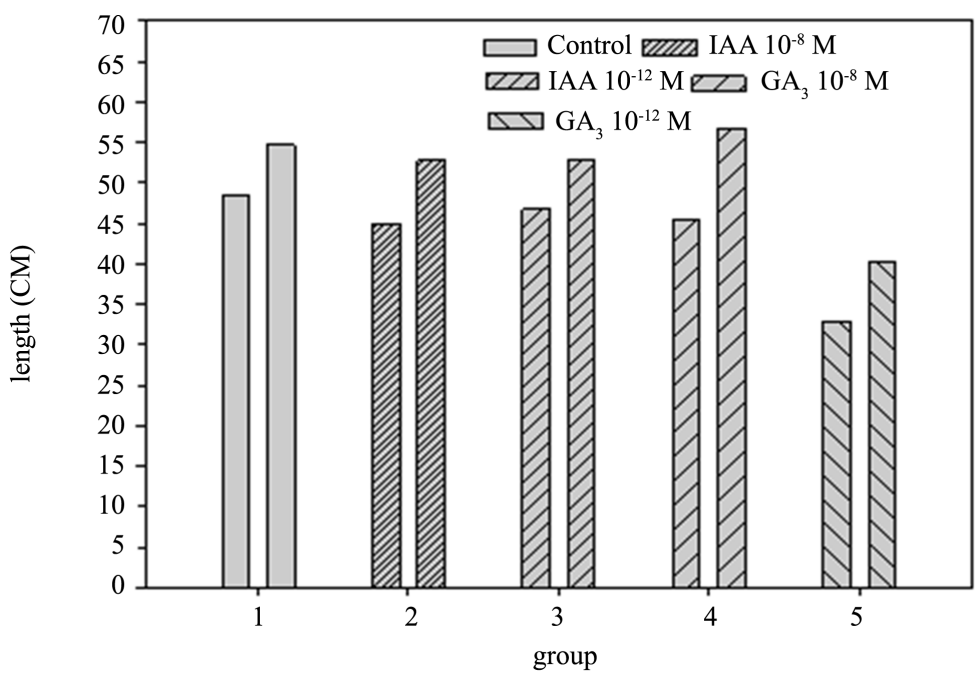

Diagram 6. Difference comparison of growth length for each group in pot culture experiment 1 .

is reported to cause the optimal growth rate and IAA $10^{-12} \mathrm{M}$ added with hormone demonstrated poorer growth, far poorer than the control group. This result shows significant higher growth of $10^{-8} \mathrm{M}$ added with hormone 
than that of $10^{-12} \mathrm{M}$. There are not enough toxins in the plants to cause death but the growth of the sunflowers is effectively enhanced [4].

\subsection{Pot Culture Experiment II}

Pot Culture Experiment II discusses the effectiveness of the addition of hormones to promote the accumulation of the heavy metal copper in sunflowers. There are three experimental groups: the control group, $\mathrm{GA}_{3}$, and IAA. The hormone spray concentration refers to the results of Pot Culture Experiment I and is determined as $10^{-8} \mathrm{M}$. No chelating agent was added in this experiment. Only a hormone is added. Heavy metal concentration accumulated in different parts of the sunflowers is addressed to know whether the hormone can effectively improve phytomediation and accumulated heavy metal volume.

\subsubsection{Pot Culture Experiment II Accumulated Heavy Metal Copper in the Roots of Each Group}

The accumulated heavy metal concentration of each plant part in the three groups of sunflowers is shown in Diagrams 7-10 (roots, stem, leaves, and flower). For the control group, the accumulated heavy metal concentra-tion of each part is respectively 27.1, 25.34, 19.02, and $15.65 \mathrm{mg} / \mathrm{kg}$. While in $\mathrm{GA}_{3}$, the accumulated heavy

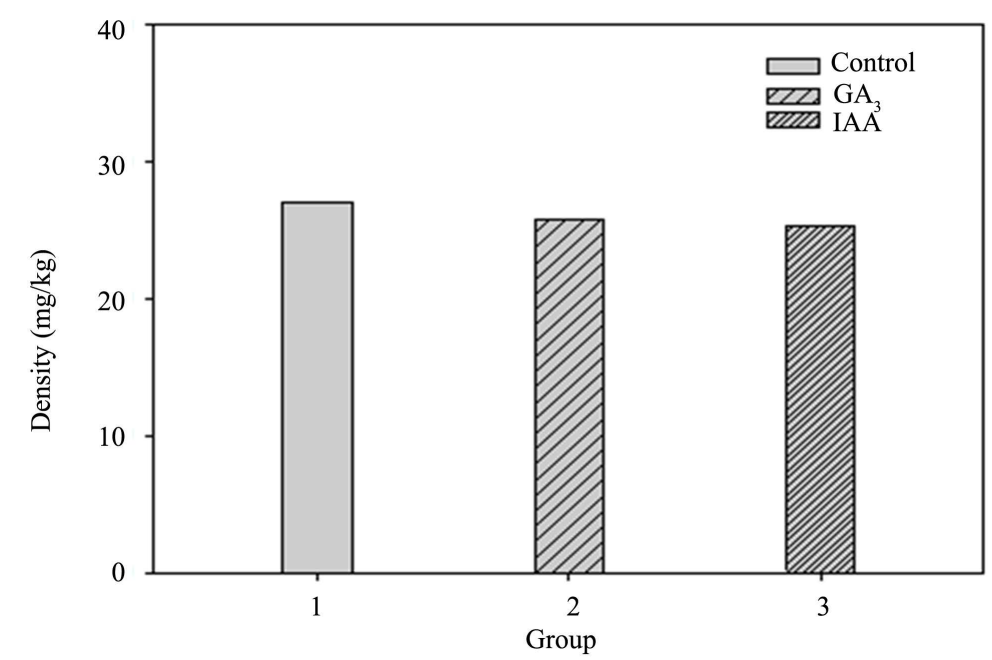

Diagram 7. Pot culture experiment II accumulated heavy metal copper in the roots of each group.

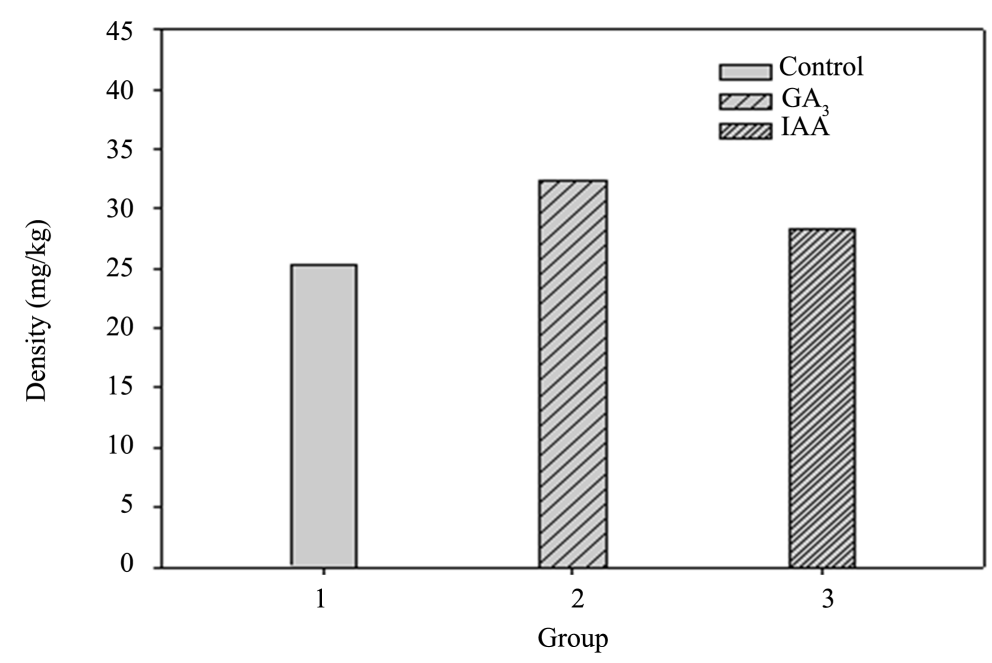

Diagram 8. Pot culture experiment II accumulated heavy metal copper in the stems of each group. 


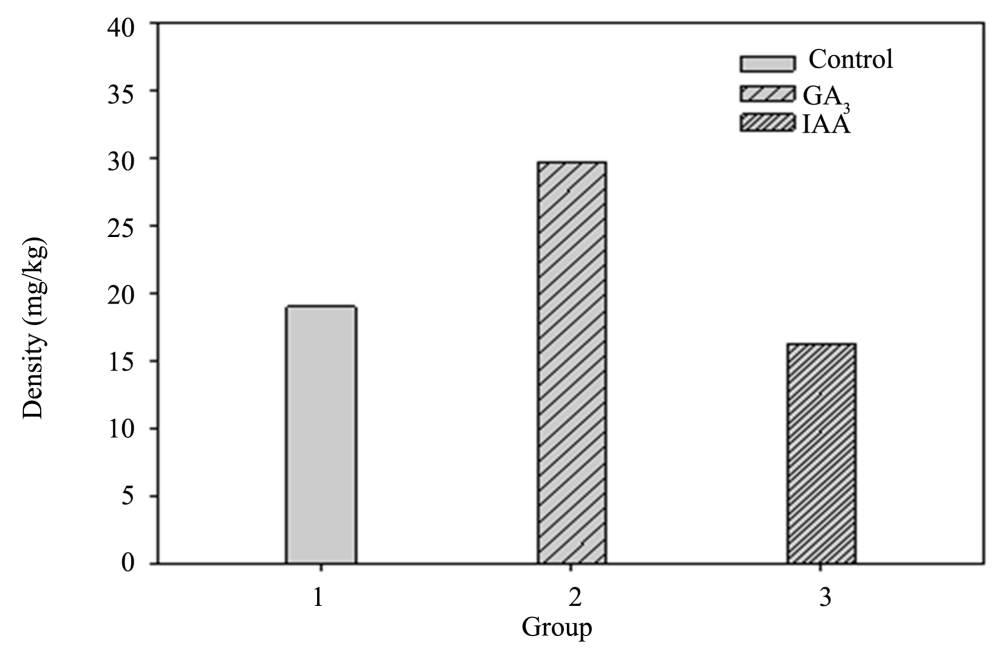

Diagram 9. Pot culture experiment II accumulated heavy metal copper in the leaves of each group.

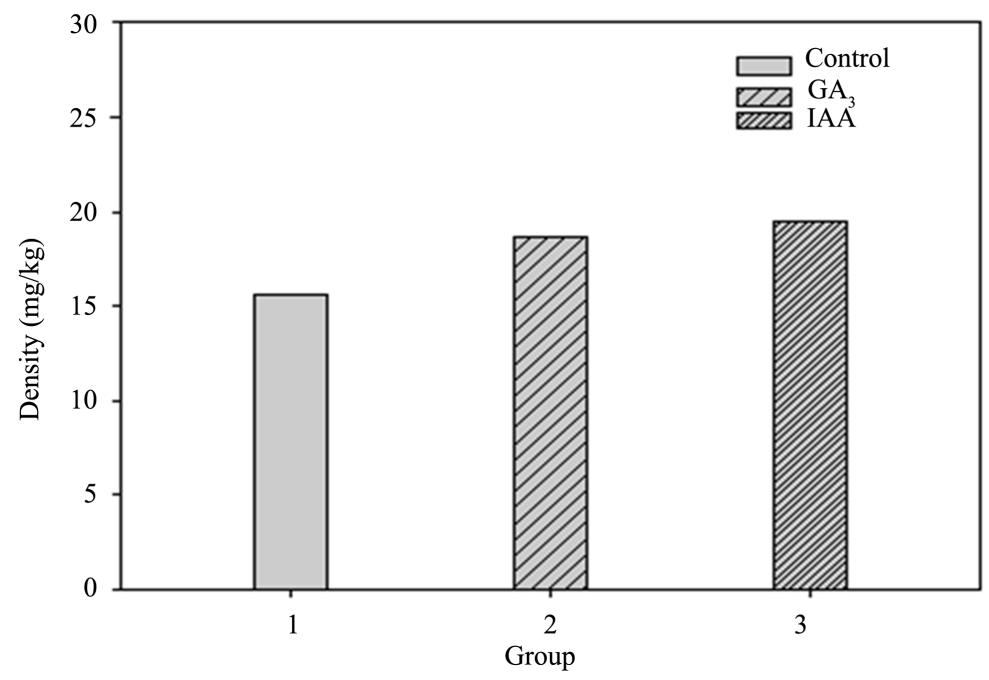

Diagram 10. Pot culture experiment II accumulated heavy metal copper in the flowers of each group.

metal concentration of each part is $25.79,32.37,29.69$, and $18.69 \mathrm{mg} / \mathrm{kg}$, respectively. IAA shows the accumulated heavy metal concentration in each part as $25.26,28.35,16.26$ and $19.47 \mathrm{mg} / \mathrm{kg}$, respectively. As shown in Diagram 9, the leaves of $\mathrm{GA}_{3}$ accumulated the highest heavy metal concentration of the three groups. It is assumed that the hormone promotes the growth of leaves and the plants transport the most nutrition to the leaves as well as the most heavy metals from the soil [5]. The accumulated heavy metal concentration of the whole plants in the three groups is shown in Diagram 11 and $\mathrm{GA}_{3}$ is identified with a significantly higher accumulation level in leaves than that of the control group. A comparison of the whole plants also shows a higher heavy metal concentration than that of the control group.

\subsubsection{Coefficient Analysis of Heavy Metal Transportation and Accumulation in Pot Culture Experiment II}

The transportation and accumulation ability of sunflowers can be demonstrated by TF and BCF as shown in Table 2. The sunflowers in the control group have a copper TF value of 1.845 while IAA added with hormone has a TF value of 1.829 with a small difference from that of the control group. $\mathrm{GA}_{3}$ performs better with the TF value of 2.329 and the metal accumulation coefficient of the sunflower root is shown as a BCF value. The sun- 


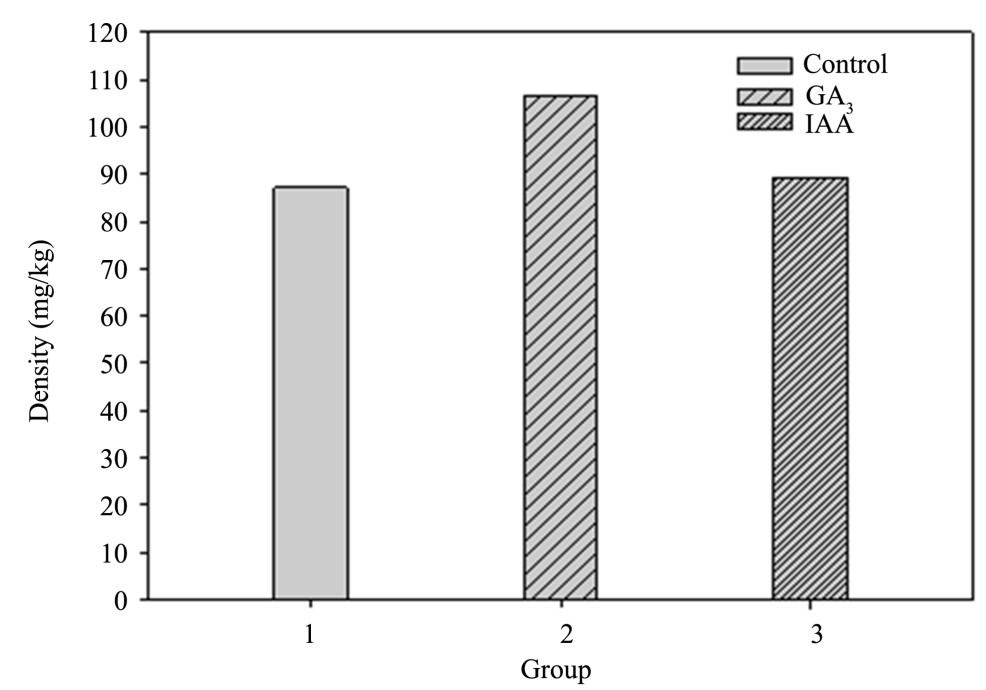

Diagram 11. Pot Culture experiment II accumulated heavy metal copper in the whole plants of each group.

Table 2. BCF, TF and PEF of the plants in the three groups.

\begin{tabular}{ccc}
\hline Factors & Treatment & Value \\
\hline BCF & Control & 0.833 \\
& $\mathrm{GA}_{3}$ & 0.744 \\
& $\mathrm{IAA}$ & 0.721 \\
$\mathrm{TF}$ & Control & 1.845 \\
& $\mathrm{GA}_{3}$ & 2.329 \\
$\mathrm{PEF}$ & IAA & 1.829 \\
& Control & 1.537 \\
& GA & 1.733 \\
\hline
\end{tabular}

flower in the control group has a copper BCF value of 0.833 while that of the other two groups added with hormone is lower with 0.744 and 0.721 , respectively [6]. It is estimated that the majority of nutrition is transported from underground and that is the reason for the decreased heavy metal concentration in the roots.

\subsection{Pot Culture Experiment III}

Pot Culture Experiment III discusses phytoattenuation, three experimental groups and a control group, $\mathrm{GA}_{3} 10^{-8}$ $\mathrm{M}$ and EDTA. The experimental soil used is from a sunflower field at National University of Kaohsiung. It attempts to simulate the accumulation ability of sunflowers planted in a practical low heavy metal environment. Between the bud formation of the sunflower seedling (about one month old) and blossom period, this study examines different sunflower growing rates and the heavy metal accumulation ability during the one-month experimental interval. Every day, photos were taken and growth length was recorded. In addition to normal irrigation, $\mathrm{GA}_{3} 10^{-8} \mathrm{M}$ was added with hormone by spraying on leaves until they became wet while EDTA before the experiment was planted in the soil. During the interval, the heavy metal concentration was measured at the seedling stage. There were a total of three stages of ten days each. On the last day of Stage 3, EDTA was found dead. The experimental purpose is to understand the heavy metal accumulation ability in soil and plants at different stages and through the concentration of heavy metal accumulated in different parts of the plant to determine BCF, TF, and PEF values. 


\subsubsection{Heavy Metal Analysis in Pot Culture Experiment III}

Photos of the control group taken between Day 1 and 30 are shown in Diagram 12, $\mathrm{GA}_{3} 10^{-8} \mathrm{M}$ is shown in Diagram 13, and EDTA is shown in Diagram 14. According to Diagram 14, EDTA is clearly dead and we ended the experiment on Day 30. Diagram 15 shows the degraded concentration of heavy metals in the soil at each stage [7]. The initial concentration and that recorded at each stage of the ten days shows a gradual declining trend at each stage, especially, during the first stage. The control group degraded from $31.63 \mathrm{mg} / \mathrm{kg}$ to 25.67 $\mathrm{mg} / \mathrm{kg}, \mathrm{GA}_{3}$ from $32.09 \mathrm{mg} / \mathrm{kg}$ to $28.33 \mathrm{mg} / \mathrm{kg}$, and EDTA from $30.65 \mathrm{mg} / \mathrm{kg}$ to $28.89 \mathrm{mg} / \mathrm{kg}$. In terms of the total degradation over the three stages, the control group degraded from $31.63 \mathrm{mg} / \mathrm{kg}$ to $23.96 \mathrm{mg} / \mathrm{kg}$, $\mathrm{GA}_{3}$ from $32.09 \mathrm{mg} / \mathrm{kg}$ to $23.04 \mathrm{mg} / \mathrm{kg}$, EDTA from $30.65 \mathrm{mg} / \mathrm{kg}$ to $25.93 \mathrm{mg} / \mathrm{kg}$ indicating the rapid growth stage between bud formation and blossom when nutrition is rapidly transported upward and the result of quick accumulation of heavy metals in the plant. At this stage, the speed of heavy metal accumulation outperforms other stages. According to the concept of phytoattenuation, when new plants are planted after the period between bud formation and blossom, it is confirmed that the heavy metal contained in the soil can be absorbed at the highest speed to reach quicker and more efficient treatment effectiveness.

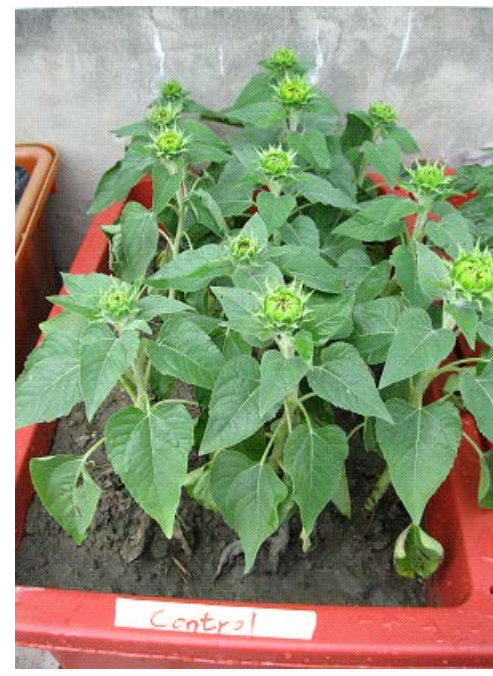

Day 1

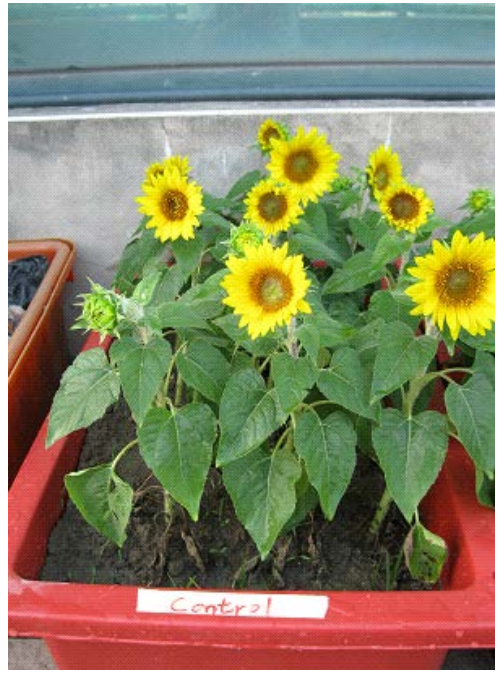

Day 15

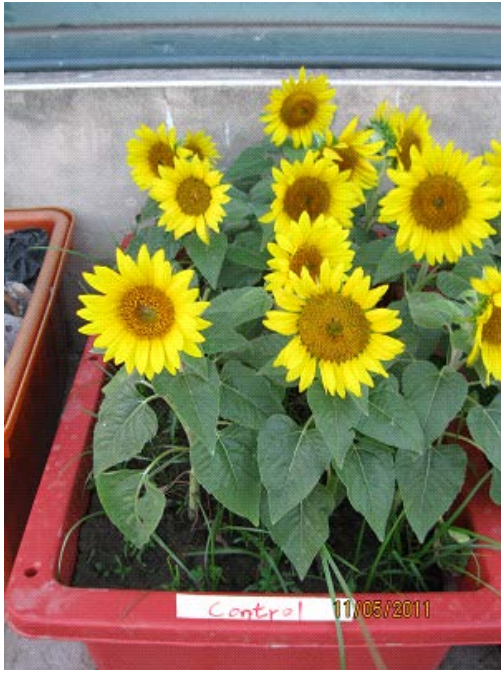

Day 30

Diagram 12. Pot Culture experiment III growth variance of the control group.

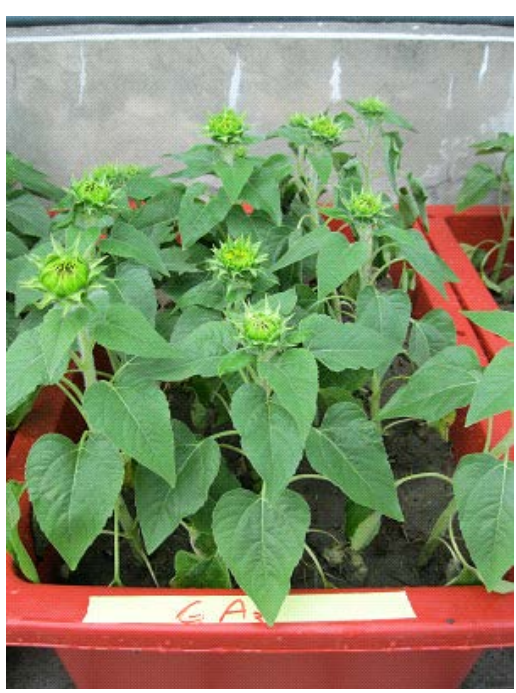

Day 1

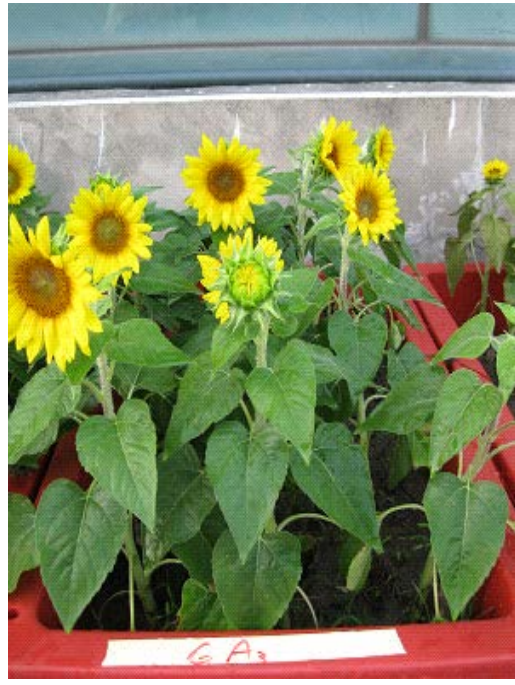

Day 15

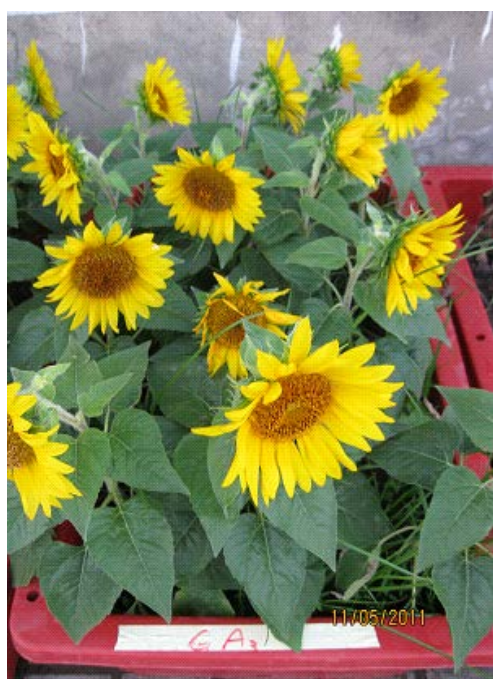

Day 30

Diagram 13. Pot Culture experiment III growth variance of $\mathrm{GA}_{3}$. 


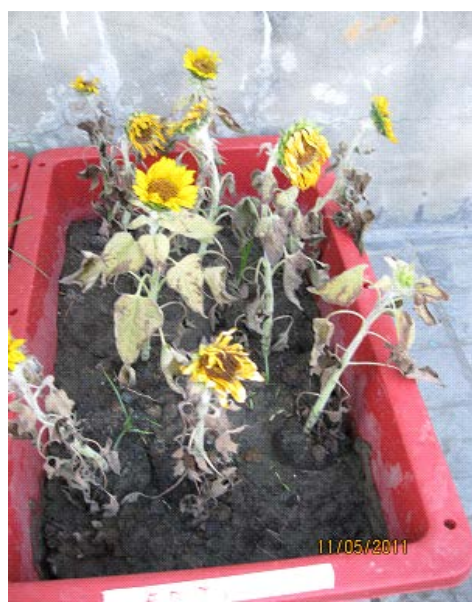

Day 1

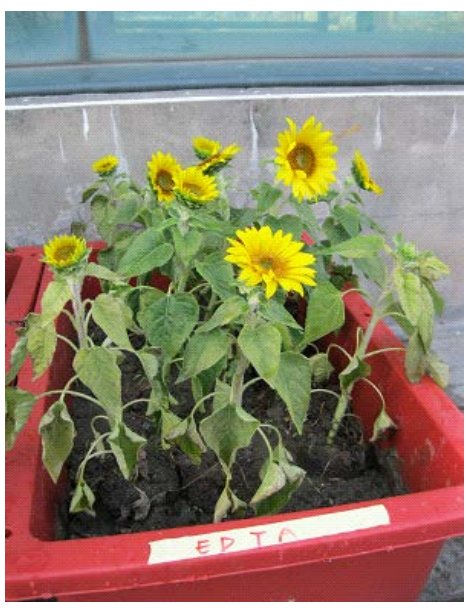

Day 15

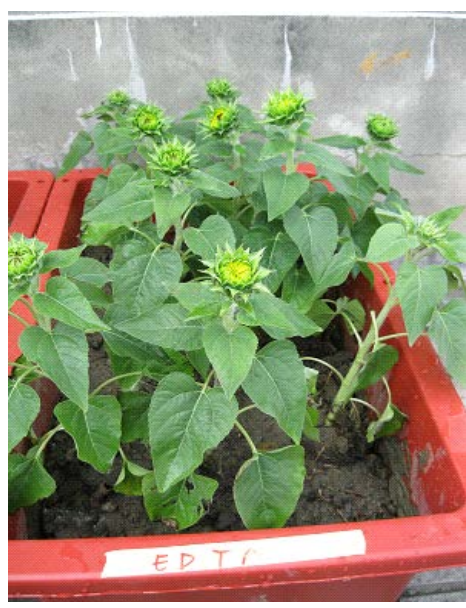

Day 30

Diagram 14. Pot culture experiment III growth variance of EDTA.

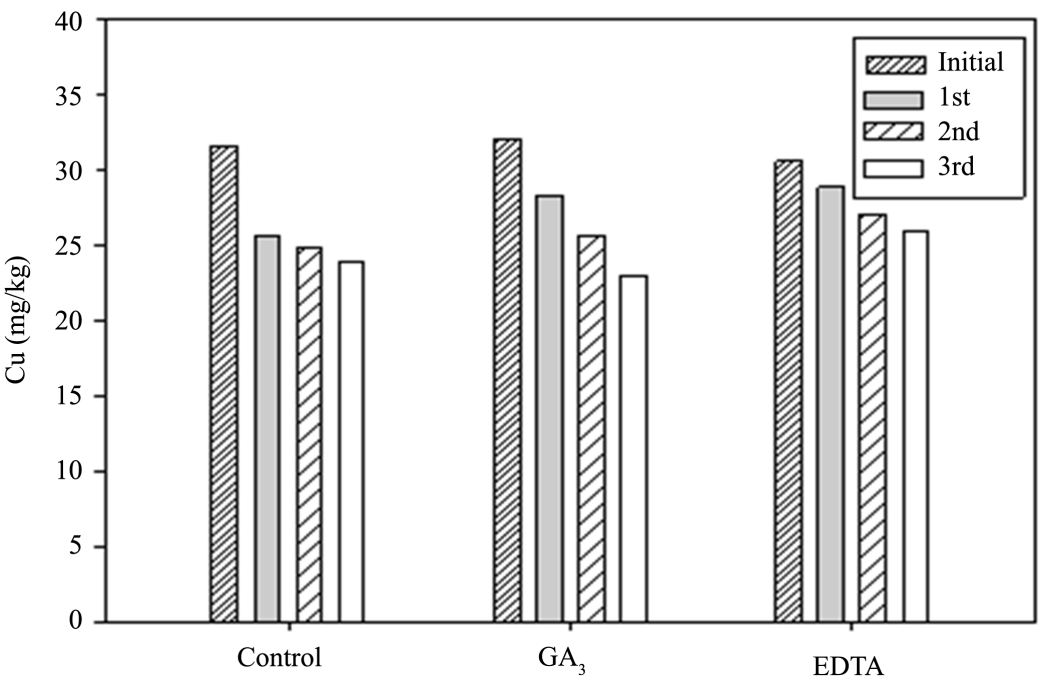

Diagram 15. Pot culture experiment III degradation concentration of heavy metal in soil at each stage.

\subsubsection{Analysis of Heavy Metal Transportation and the Accumulation Coefficient in Pot Culture Experiment III}

Diagram 16 shows heavy metal copper accumulation in plants at each stage and $\mathrm{GA}_{3}$ is found to have a significantly higher heavy metal concentration in the roots than that of the other two groups. Even at Stage 3, EDTA resulted in a toxicity level that sunflower plants could not resist and the concentration of $\mathrm{GA}_{3}$ on the parts on the ground is higher than that of EDTA. This photo clearly shows that the functioning part of $\mathrm{GA}_{3}$ is on the leaf and the nutrition of the plant is transported to the parts on the ground resulting in a much higher concentration than that on the root. Table 3 indicates BCF, TF, and PEF values at each stage [8]. Because the functioning part of $\mathrm{GA}_{3}$ is the leaf and the TF value in the three stages are respectively 3.191, 2.558, and 2.582, which is significantly better than that of control group, 2.272, 2.071 and 2.204 as well as that of EDTA, 2.511, 1.997, and 1.432. Due to the high TF value, its PEF value surpassed that of the other two groups and $\mathrm{GA}_{3}$ has a PEF value at each of the three stages of 2.924, 2.732, and 2.989. Table 3 indicates a better performance than that of control and EDTA group [9].

\section{Conclusions}

With the hormone addition to $10^{-8} \mathrm{M}$, Pot Culture Experiment II examines the concentration of heavy metals in 


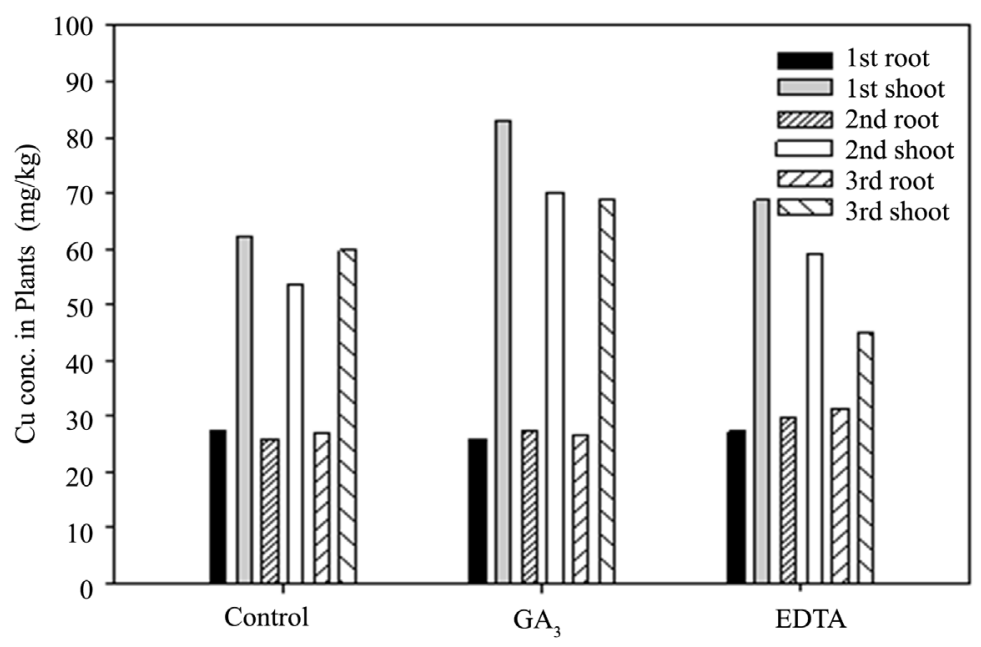

Diagram 16. Pot culture experiment III accumulation of heavy metal copper in plants at each stage.

Table 3. BCF, TF, and PEF at each stage.

\begin{tabular}{ccccc}
\hline Factors & Treatment & $1^{\text {st }}$ & 2nd & 3rd \\
\hline BCF & Control & 1.065 & 1.041 & 1.131 \\
& GA $_{3}$ & 0.916 & 1.068 & 1.158 \\
& EDTA & 0.947 & 1.094 & 1.208 \\
TF & Control & 2.271 & 2.071 & 2.204 \\
& GA & 3.191 & 2.558 & 2.582 \\
PEF & EDTA & 2.511 & 1.997 & 2.432 \\
& Control & 2.418 & 2.156 & 2.993 \\
\hline
\end{tabular}

different parts of the plant. Experimental results indicate $\mathrm{GA}_{3}$ on the leaf accumulates a concentration of 29.69 $\mathrm{mg} / \mathrm{kg}$ much higher than the $19.05 \mathrm{mg} / \mathrm{kg}$ of the control group and $16.26 \mathrm{mg} / \mathrm{kg}$ of IAA. It is confirmed that $\mathrm{GA}_{3}$, due to the functioning part on the leaf, accumulates a large amount of heavy metal from the soil when nutrition is transported to the leaf. Although a large amount of heavy metal is accumulated in the leaf, yet according to the growth observation in the whole experiment, $\mathrm{GA}_{3}$ still effectively helped plant growth and for the total accumulation of the whole plant, $\mathrm{GA}_{3}$ outperformed the control group. It is concluded that $\mathrm{GA}_{3}$ at the concentration of $10^{-8} \mathrm{M}$ can effectively help the growth of sunflower plants and the accumulation of copper outperformed that of the control group.

In Pot Culture Experiment II, the function of $\mathrm{GA}_{3}$ on the leaf results in a significant increase of TF in the sunflower plants. The $\mathrm{GA}_{3}$ added group has a TF value of 2.329, which is higher than the 1.845 of the control group and the 1.829 of IAA. The accumulation coefficient of heavy metal can be shown as BCF; the BCF of the control group is 0.833. The other two groups added with hormone have a lower BCF, 0.744 and 0.721 , lower than that of the control group. It is assumed that because the transportation of most nutrition to the ground and the concentration of heavy metals accumulated in the root decreased accordingly.

Pot Culture Experiment III examines phytoattenuation in a one-month experimental interval that is divided into three stages. At Stage 1 (Day 1 - Day 10), the most significant decreasing trend was identified. It is known that when a sunflower plant is at the growth stage, its rapid growth is accompanied with a huge transportation of heavy metals accumulated in the soil. After the flower blossoms, the growth stage ends and the accumulation of 
heavy metals reduces accordingly. Based on the concept of phytoattenuation, when new plants are repeatedly used for replacement between bud formation and blossom, heavy metals in the soil are confirmed to be absorbed at the quickest speed to reach better and more efficient treatment effectiveness.

\section{References}

[1] Li, K.H. (2012) A Study on the Improvement of Phytomediation on Treatment Effectiveness of Heavy Metal by Energy Plant Sunflower with Calcium Peroxide and Phytohormone. Unpublished MA Thesis, Department of Civil and Environmental Engineering, National University of Kaohsiung, Kaohsiung City.

[2] Bruno-Fernando, F.P., Cleide-Aparecida, A., Solange, R., Ana-Maria, M.A.L. and Antonio, P.G. (2007) Pb-Phytoextraction by Maize in a Pb-EDTA Treated Soil. Scientia Agricola, 64, 52-60. http://dx.doi.org/10.1590/S0103-90162007000100008

[3] Evangelou, M.W.H., Bauer, U., Ebel, M. and Schaeffer, A. (2007) The Influence of EDDS and EDTA on the Uptake of Heavy Metals of $\mathrm{Cd}$ and $\mathrm{Cu}$ from Soil with Tobacco Nicotianatabacum. Chemosphere, 68, 345-353. http://dx.doi.org/10.1016/j.chemosphere.2006.12.058

[4] Israr, M. and Sahi, S.V. (2008) Promising Role of Plant Hormones in Translocation of Lead in Sesbaniadrummondii Shoots. Environmental Pollution, 153, 29-36. http://dx.doi.org/10.1016/j.envpol.2007.12.029

[5] Sheng, X.F., Xia, J.J., Jian, C.Y., He, L.Y. and Qian, M. (2008) Characterization of Heavy Metal-Resistant Endophytic Bacteria from Rape (Brassica napus) Roots and Their Potential in Promoting the Growth and Lead Accumulation of Rape. Environmental Pollution, 156, 1164-1170. http://dx.doi.org/10.1016/j.envpol.2008.04.007

[6] Ma, Y., Rajkumar, M. and Freitas, H. (2009) Inoculation of Plant Growth Promoting Bacterium Achromobacterxylosoxidans Strain Ax10 for the Improvement of Copper Phytoextraction by Brassica juncea. Journal of Environment Management, 90, 831-837. http://dx.doi.org/10.1016/j.jenvman.2008.01.014

[7] Koo, S.Y. and Cho, K.S. (2009) Isolation and Characterization of a Plant Growth-Promoting Rhizobacterium, Serratia sp. SY5. Journal of Microbiology and Biotechnology, 19, 1431-1438.

[8] Fässler, E., Evangelou, M.W., Robinson, B.H. and Schulin, R. (2010) Effect of Indole-3-Acetic Acid (IAA) on Sunflower Growth and Heavy Metal Uptake in Combination with Ethylene Diamine Disuccinic Acid (EDDS). Chemosphere, 80, 901-907. http://dx.doi.org/10.1016/j.chemosphere.2010.04.077

[9] Hadi, F., Bano, A. and Fuller, M.P. (2010) The Improved Phytoremediation of Lead (Pb) and the Growth of Maize (Zea mays L.): The Role of Plant Growth Regulators (GA 3 and IAA) and EDTA Alone and in Combinations. Chemosphere, 80, 457-462. http://dx.doi.org/10.1016/j.chemosphere.2010.04.020 